\title{
Prognostic factors in the surgical treatment of intracanalicular primary optic nerve sheath meningiomas
}

\author{
Marcio S. Rassi, MD, ${ }^{1}$ Sashank Prasad, MD, ${ }^{2}$ Anil Can, MD, ${ }^{1}$ Svetlana Pravdenkova, MD, PhD, ${ }^{3}$ \\ Rami Almefty, MD, ${ }^{4}$ and Ossama Al-Mefty, MD ${ }^{1}$ \\ Departments of ${ }^{1}$ Neurosurgery and ${ }^{2}$ Neurology, Brigham and Women's Hospital, Harvard Medical School, Boston, \\ Massachusetts; ${ }^{3}$ Arkansas Neuroscience Institute, St. Vincent Infirmary, Little Rock, Arkansas; and ${ }^{4}$ Division of Neurological \\ Surgery, Barrow Neurological Institute, St. Joseph's Hospital and Medical Center, Phoenix, Arizona
}

OBJECTIVE Although meningiomas frequently involve the optic nerve, primary optic nerve sheath meningiomas (ONSMs) are rare, accounting for only $1 \%$ of all meningiomas. Given the high risk of vision loss with these tumors, surgical intervention is seldom considered, and radiation or observation is commonly applied. Here, the authors describe the visual outcomes for a series of patients who were treated with surgery aiming at maximal tumor resection and highlight their prognostic factors.

METHODS The authors retrospectively analyzed the data for 8 patients with intracanalicular ONSMs who had been surgically treated by the senior author (O.A.) between 1998 and 2016. Meningiomas extending into the optic canal from the intracranial cavity (i.e., clinoid, sphenoid wing, tuberculum sellae, diaphragma sellae) were excluded. Diagnosis was based on ophthalmological, radiological, and intraoperative findings, which were confirmed by the typical histological findings. Preoperative, postoperative, and follow-up visual assessments were performed by neuro-ophthalmologists in all cases.

RESULTS The patients included 7 females and 1 male. The mean age at diagnosis was 45.1 years (range 25.0-70.0 years). Mean duration of follow-up was 38.9 months (range 3.0-88.0 months). All patients reported visual complaints, and all had objective evidence of optic nerve dysfunction. Their evaluation included visual field, visual acuity, funduscopy, and retinal fiber thickness. Total resection was obtained in 4 cases. Comparing preoperative and postoperative visual function revealed that 4 patients had improvement at the last follow-up, 1 patient had stable vision, and 3 patients had decreased function but none had total vision loss. All patients with good preoperative visual acuity maintained this status following surgical treatment. There was no surgical mortality or infection. Operative complications included binocular diplopia in 4 patients, which remitted spontaneously.

CONCLUSIONS Surgery can play a beneficial role in the primary treatment of ONSM, especially lesions located in the posterior third of the nerve. Total removal can be achieved with vision preservation or improvement, without major surgical complications, especially at early stages of the disease. Patients with good preoperative vision and CSF flow in the optic sheath have better chances of a favorable outcome than those with poor vision.

https://thejns.org/doi/abs/10.3171/2018.4.JNS173080

KEYWORDS optic nerve; meningioma; optic sheath; orbital tumor; skull base tumor; oncology

\begin{abstract}
As is true in all other intracranial tumors, an early diagnosis [of optic foramen tumors] simplifies the operative procedure, reduces its dangers and affords the patient the best chance of life and preservation of function.
\end{abstract}

- Walter E. Dandy, $1922^{14}$

Meningiomas represent approximately $35 \%$ of all tumors involving the optic nerve. ${ }^{6,52}$ Among all intraorbital meningiomas, approximately $90 \%$ originate intracranially and extend through the optic canal into the orbit. ${ }^{10}$ The remaining $10 \%$ arise from the arachnoid of the intraorbital optic nerve and are classified as optic nerve sheath meningiomas (ONSMs). ${ }^{15,44,51}$ These tumors are rare, corresponding to only $1 \%$ of all orbital lesions, ${ }^{15,40}$ and their origin within the optic canal is infrequent. ${ }^{10}$ They are often subdural and small at their first appearance. With progression, they tend to invade the dural sheath and extend into the orbital soft tissue or even the orbital walls. ${ }^{41}$ When oc-

ABBREVIATIONS GTR = gross-total resection; ONSM = optic nerve sheath meningioma .

SUBMITTED December 7, 2017. ACCEPTED April 2, 2018.

INCLUDE WHEN CITING Published online September 21, 2018; DOI: 10.3171/2018.4.JNS173080. 
curring within the optic canal, ONSMs were once referred to as "the impossible meningioma" because of the difficulties in the diagnosis and surgical treatment of tumors in that location..$^{45}$

The management of ONSM is controversial. Left untreated, progressive vision loss will occur, often as a result of direct tumoral compression of the nerve, compromise of its vasculature, and in some cases direct neoplastic infiltration of the optic nerve. ${ }^{41}$ Current management for most patients with ONSM involves observation when visual function is relatively preserved, with minor field deficits and acuity $\geq 20 / 40 .{ }^{17,30,35,47,52}$ If visual function declines, fractionated stereotactic radiation is typically offered to try to mitigate further vision loss, a procedure that, according to several authors, provides acceptable vision stabilization and progression control, despite its toxicity., $1,2,3,32,39$ Inherently, radiosurgery is not applicable due to the risk of vision loss. ${ }^{39}$

In general, surgery has been avoided for ONSMs given the risk of perioperative vision loss. ${ }^{6,25,39,52}$ In 1938, Cushing and Eisenhardt described the drastic measure of resecting the optic nerve as the primary treatment for meningiomas involving the nerve. ${ }^{13}$ More recent reports have still failed to show an advantage of surgery over other treatment options because of the high morbidity from vision loss and frequent tumor recurrences. ${ }^{18,47,52}$ Therefore, surgical intervention has generally been reserved for extensive neoplasms that cause disfiguring proptosis or pose a high risk of intracranial extension. In such cases, tumor debulking with decompression of the optic apparatus has been described. . $5,33,34,37^{-13}$

A different approach, one of the early surgical interventions, was first espoused in 1950 by Craig and Gogela, who stated, "There is every reason to believe that with early recognition of these lesions and their prompt removal, failing vision may be controlled and possibly even improved or restored." ${ }^{11}$ We believed that with appropriate techniques and expertise, early surgical intervention as a primary treatment can not only stop disease progression and reduce the risk of subsequent vision loss, but also, to some extent, reverse visual deficits that have already occurred. Therefore, we herein present the outcomes of a series of patients surgically treated for ONSM with the goal of gross-total resection (GTR) and report the factors associated with a good outcome.

\section{Methods \\ Data Collection}

Under institutional review board (IRB) approval, we retrospectively analyzed the data for 8 patients harboring primary ONSM within the optic canal who had been surgically treated by the senior author (O.A.) between 1998 and 2016. Only tumors originating from the optic nerve sheath were included in this series; we excluded meningiomas extending into the optic canal (i.e., those arising from the clinoid, tuberculum sellae, sphenoid wing, and diaphragma sellae). Diagnosis of the tumor origin was based on preoperative images and intraoperative findings. The diagnosis of meningiomas was confirmed by typical histological features. Preoperative imaging included thin-slice
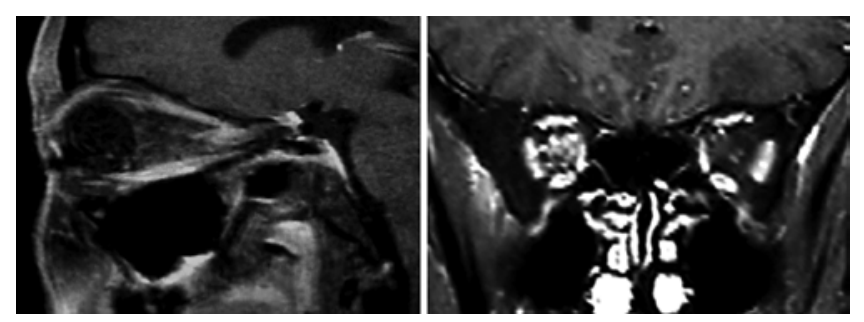

FIG. 1. Postcontrast T1-weighted MRI studies. Left: Oblique view depicting a meningioma along the posterior third of the right optic nerve. Right: Coronal view showing the radial distribution of the tumor along the optic nerve circumference.

bone window CT and MRI studies. A specialized coronal MRI sequence orthogonal to the optic canal often offered the best image for evaluating tumor extension along the nerve (Fig. 1).

Neuro-ophthalmologists performed detailed ophthalmological evaluations preoperatively, postoperatively, and on follow-up in all cases. Best corrected visual acuity was tested with a Snellen eye chart. ${ }^{29}$ Visual fields were analyzed with standard automated Humphrey $24^{\circ}$ or $30^{\circ}$ perimetry, and results were accepted as reliable when the occurrence of false-negative and false-positive results did not exceed $30 \%$.

\section{Surgical Considerations}

Through a unilateral supraorbital craniotomy, ${ }^{3}$ the optic canal is exposed and unroofed extradurally using a highspeed drill. If necessary, an anterior clinoidectomy is performed to allow better exposure of tumors with inferior extension. Drilling is carried out using a fine diamond bit under constant irrigation to avoid heating the bone. Pressure streaming irrigation is avoided over the optic nerve. Bone is removed layer by layer; hence, the nerve tends to be more compressed in the canal. The optic nerve is not manipulated; coagulation is not used, and bleeding is controlled with irrigation, although streaming irrigation on the nerve is avoided. No pharmacological agent, such as papaverine or steroids, is used. The annulus of Zinn is opened, releasing the nerve and allowing the tumor to be followed through its intraorbital extension. Under high magnification, a plane of arachnoidal dissection is established, and tumor is gently resected from around the nerve. The most critical site is the area of the central retinal artery entry, usually at the junction of the middle and anterior thirds of the intraorbital portion of the optic nerve. ${ }^{46}$

\section{Results}

The patients included 7 females and 1 male. The mean age at diagnosis was 45.1 years (range $25.0-70.0$ years). Mean follow-up was 38.9 months (range 3.0-88.0 months). The tumor arose de novo in 7 cases $(87.5 \%)$, and 1 patient had undergone prior treatment with subtotal resection followed by stereotactic radiation. No other patients had received radiation prior to their surgical treatment.

All patients reported visual complaints: vision loss in $75 \%$, followed by blurred vision and double vision in $20 \%$. The full list of chief complaints is presented in Table 1. At presentation, visual performance was good (LogMAR 
TABLE 1. Demographics and clinical and tumor presentation

\begin{tabular}{ccclcl}
\hline $\begin{array}{c}\text { Case } \\
\text { No. }\end{array}$ & $\begin{array}{c}\text { Age } \\
\text { (yrs) }\end{array}$ & Sex & Initial Symptoms & Laterality & \multicolumn{1}{c}{ Tumor } \\
\hline 1 & 52 & F & Vision loss, diplopia & Rt & De novo \\
\hline 2 & 62 & F & Vision loss & Lt & De novo \\
\hline 3 & 44 & F & $\begin{array}{l}\text { Vision loss, diplopia, } \\
\text { ptosis }\end{array}$ & Lt & De novo \\
\hline 4 & 27 & M & Vision loss, seizures & Rt & Previously treated \\
\hline 5 & 70 & F & Blurred vision & Rt & De novo \\
\hline 6 & 33 & F & Blurred vision & Bilat & De novo \\
\hline 7 & 48 & F & Vision loss & Lt & De novo \\
\hline 8 & 25 & F & Vision loss & Rt & De novo \\
\hline
\end{tabular}

Snellen equivalent $\geq 0.5)$ in 6 patients $(75 \%)$ and fair $(<0.5$ to $>0.1$ ) in 2 patients $(25 \%)$; none of the patients had poor $(\leq 0.1$ to 0$)$ preoperative vision. ${ }^{37}$

Gross-total resection, which was the aim of surgery in all cases, was achieved in 4 (50\%; Table 2). Tumor occupied the optic canal in all cases. To describe the extent of tumor involvement along the intraorbital optic nerve, we divided this portion into three segments: anterior, middle, and posterior. The posterior third was involved in all cases, the middle third in 4 , and the anterior third in 2 cases. One patient had a bilateral ONSM extending en plaque across the planum sphenoidale (Fig. 2).

Among the patients with a good preoperative visual performance, all sustained this status during follow-up. At the last follow-up, 4 patients (50\%) demonstrated improvement in visual function as compared to preoperatively, 1 patient had no change in vision and remained stable, and 3 patients experienced visual decline. Table 2 features visual outcomes, tumor locations, and extent of resection. A Supplementary Table shows the actual pre- and postoperative visual fields along with the data displayed in Table 2.

There was no surgical mortality or neurological or systemic complications. Operative complications included binocular diplopia (4 patients) that spontaneously recovered within the follow-up period. No tumor recurrence was observed at the last follow-up in any of the patients.
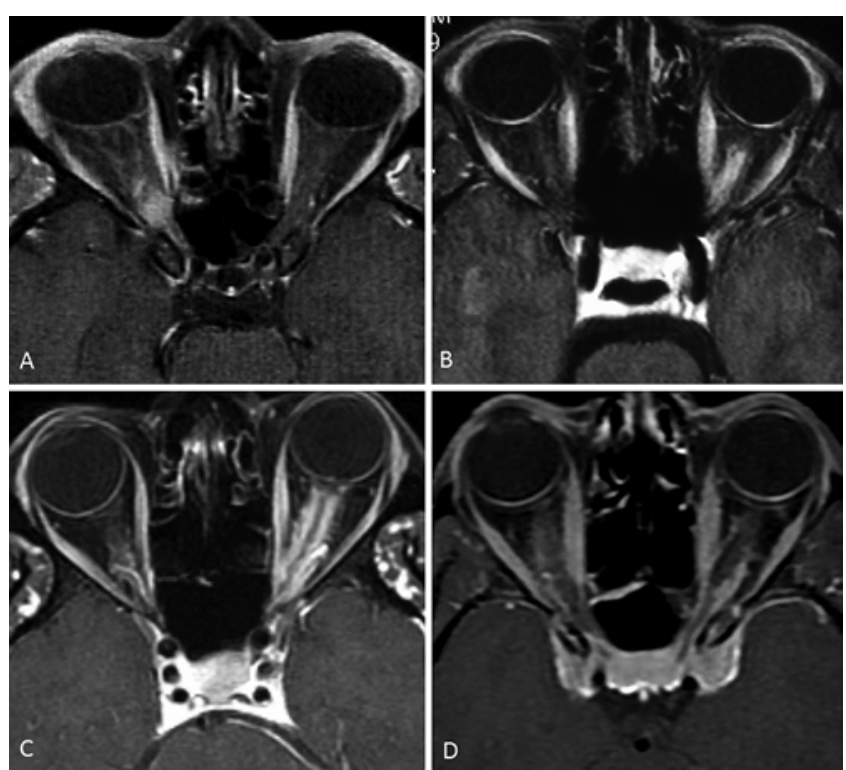

FIG. 2. Postcontrast axial T1-weighted MRI studies revealing intracanalicular lesions. A: Tumor extending into the posterior third of the optic nerve. B: Tumor extending into the middle third of the optic nerve. $\mathbf{C}$ : Tumor extending into the anterior third of the optic nerve. D: Bilateral involvement of the optic nerve by tumor.

\section{Discussion}

\section{Clinical Management}

The high female predominance $(87.5 \%)$ and mean age of 45.1 years at diagnosis in our patient series are consistent with most reports in the literature, in which ONSMs occur predominantly in females, tend to present earlier than intracranial meningiomas, ${ }^{4,7,9,10,12,15,17,34,35,37,44,47,52}$ and, as expected, have vision loss as the chief complaint., $15,21,34,37,52$

In a major literature review by Dutton in 1992, only $26(5.7 \%)$ of 454 unilateral ONSMs were located within the optic canal..$^{15}$ The natural course of ONSM, as with all meningiomas, is progressive growth in different patterns.$^{20}$ Hence, if these lesions are left untreated, progressive vision loss and proptosis are common consequences. Furthermore, progression can, by intracranial extension,

TABLE 2. Preoperative and postoperative visual acuities and visual fields, extent of resection, and visual outcomes

\begin{tabular}{cccccccccc}
\hline Case No. & Preop VA & Preop VF (MD) & Postop VA & Postop VF (MD) & Tumor Extension* & EOR & Last FU (mos) & Final Visual Status \\
\hline 1 & $20 / 40$ & -20.5 & NA & -12.52 & Pst & GTR & 3.76 & Improved \\
\hline 2 & $20 / 50$ & -20.93 & $20 / 400$ & -31.88 & Ant & STR & 50.46 & Worsened \\
\hline 3 & $20 / 30$ & NA & $20 / 30$ & NA & Pst & GTR & 25.53 & Stable \\
\hline 4 & $20 / 30$ & -29.87 & $20 / 15$ & -10.24 & Mid & GTR & 63.06 & Improved \\
\hline 5 & $20 / 40$ & -3.89 & $20 / 40$ & -17.94 & Pst & GTR & 5.0 & Worsened \\
\hline 6 & $20 / 20(\mathrm{rt})$, & $-4.12(\mathrm{rt})$, & $20 / 20(\mathrm{rt})$, & $-1.16(\mathrm{rt})$, & Mid & STR & 50 & Improved \\
& $0 / 20(\mathrm{lt})$ & $-8.08(\mathrm{lt})$ & $20 / 20(\mathrm{lt})$ & $-2.3(\mathrm{lt})$ & & & & \\
\hline 7 & $20 / 50$ & NA & EC & -30.04 & Ant & STR & 88.3 & Worsened \\
\hline 8 & $20 / 25$ & -10.27 & $20 / 20$ & -10.57 & Pst & STR & 3.06 & Improved \\
\hline
\end{tabular}

$\mathrm{Ant}=$ anterior; $\mathrm{EC}=$ eccentric viewing; $\mathrm{EOR}=$ extent of resection; FU = follow-up; $\mathrm{MD}=$ mean deviation; $\mathrm{Mid}=$ middle; $\mathrm{NA}=$ not available; Pst = posterior; STR = subtotal resection; $\mathrm{VA}=$ visual acuity; $\mathrm{VF}=$ visual field.

${ }^{*}$ Along the intraorbital part of the optic nerve. 
lead to subchiasmatic extension and involvement of the contralateral eye.

Currently, management commonly involves initial observation for patients with good to moderate vision loss, followed by radiation therapy when progression is detected. ${ }^{17,30,35,47,52}$ Surgery has been reserved for patients with disfiguring proptosis or intracranial extension, when partial removal might be offered, followed or not by radiation. $^{25,33,34,37}$ Observation, however, can lead to eventual progressive visual deterioration and blindness. ${ }^{15,22,34,47}$ Turbin et al. reported a multicenter review of 64 cases of ONSM, in which 13 patients were solely observed, and all had progressive visual decline during follow-up. ${ }^{47}$ In a study conducted by Roser et al., 2 patients refused surgical treatment and were followed up with MRI and ophthalmological evaluation every 6 months; after 38 months and 60 months, respectively, the patients lost complete vision in the affected eye. ${ }^{34}$

Several authors have reported positive outcomes in terms of improving or stabilizing visual function with radiation therapy. ${ }^{2,4,5,42,47}$ In a report on 64 patients treated with different modalities, Turbin et al. concluded that the best long-term visual outcomes were achieved with fractionated radiotherapy alone as the primary treatment, as compared to those attained with observation, surgery alone, or surgery with adjuvant radiation. ${ }^{47}$ The complication rate was $33 \%$, including retinopathy, vascular occlusion, and temporal lobe atrophy.

In 2012, Adams et al. suggested that early radiotherapy would be the optimal treatment for ONSM, reporting 78\% improvement and $89 \%$ stabilization of vision among 18 patients treated with conventional conformal radiotherapy (5 patients did not have useful vision before treatment). Acute radiation side effects were experienced by 11 patients, and late effects occurred in 8 patients. ${ }^{2}$

In 2013, Brower et al. reported on a series of 15 patients treated with radiotherapy, $27 \%$ of whom experienced vision improvement and $60 \%$ of whom had stable vision following treatment; retinopathy was the only complication, occurring in $13 \%$ of the patients. ${ }^{5}$ Neither did these authors find tumor progression during the follow-up; however, there was no change in the tumor size in $93 \%$ of their cases. This finding, the inability of radiotherapy to promote any tumor regression in most cases, has been reported in several studies. $5,37,43$

\section{Surgical Management}

Near a century ago, Dandy advocated the need for early recognition and treatment of intracanalicular lesions as he described the cases of two children with intracanalicular ONSMs who had been surgically treated, resulting in great improvement of visual function. ${ }^{14}$ Since radiological and intraoperative findings often demonstrate tumor compressing the nerve within its relatively immovable dural border, it has been suggested that visual improvement may be possible with plain decompression of the nerve. On the basis of such a theory, Wright reported on 2 cases of optic nerve decompression via resection of the optic sheath; however, both patients experienced visual decline during the follow-up. ${ }^{50}$ Saeed et al. had similar findings in their study of 47 patients who were primarily treated with surgery. Among the 10 patients who had undergone plain optic nerve decompression, 8 lost their vision during follow-up. ${ }^{35}$

Although surgical intervention for tumor removal has been linked to an unfavorable visual outcome, ${ }^{47}$ visual improvement and stabilization through resection has been described as well. 9,16,21,28,34,48,52 Roser et al. reported on 22 patients with ONSM treated with surgery. ${ }^{34}$ In all of the blind patients, the optic nerve was transected; all 16 patients with functional vision underwent partial resection of their tumors. At the last follow-up, $50 \%$ of the patients had experienced visual improvement or stabilization. The authors asserted that the goal of surgery should be to remove as much tumor as possible, with opening of the optic canal and without manipulating the optic nerve. More lately, Schick and Hassler stated that tumor left inside the optic canal can be the cause of either recurrence or the absence of visual improvement after surgery. ${ }^{38}$ Our findings indicated a higher incidence of visual stability and improvement in patients with good preoperative vision. A similar finding was reported by Schick et al. in 2004. ${ }^{37}$

Furthermore, we noticed that tumors located in the posterior and middle thirds of the intraorbital optic nerve are more suitable for GTR and have a more favorable visual outcome than those extending to the anterior third. All patients with tumors limited to the posterior third of the nerve were treated with GTR, except for 1 patient who had a portion of the lesion very adherent to the intracanalicular inferior part of the nerve. Patients presenting with tumors extending to the anterior third of the nerve had a worse visual outcome. This result may be related to the involvement of the central retinal artery and optociliary arteries when tumors extend beyond the middle third. In fact, in 1 case, it was possible to notice signs of ischemia of the nerve on the preoperative images (Fig. 3).

All of our patients with a good preoperative visual performance had sustained this status during follow-up, whereas 2 patients with fair preoperative vision had decreased to poor vision (Table 3 ).

\section{Surgical and Anatomical Considerations Vascularity}

Several authors have reported that the difficulty in successful tumor removal with a good visual outcome lies mostly in preserving the optic nerve's vasculature, especially the central retinal artery, ${ }^{4,12}$ whereas other authors have suggested that manipulation of the optic nerve during surgery could lead to vasospasm of its vasa nervorum, with consequent ischemia. ${ }^{34}$ In 1949, Walsh suggested that a meningioma encircling the optic nerve and the nerve itself have a common vascular supply that could be compromised during tumor removal. ${ }^{49}$

The peripheral vascular network of the optic nerve has numerous anastomoses; therefore, impairment of visual function is more likely to occur when injury involves terminal vessels of the periphery or the longitudinal system of the central retinal artery. ${ }^{19}$ In the intracanalicular part of the optic nerve, there is no axial artery, only precapillaries, which are less numerous than at the level of the optic tract and more dense and irregular as we move toward the optic 

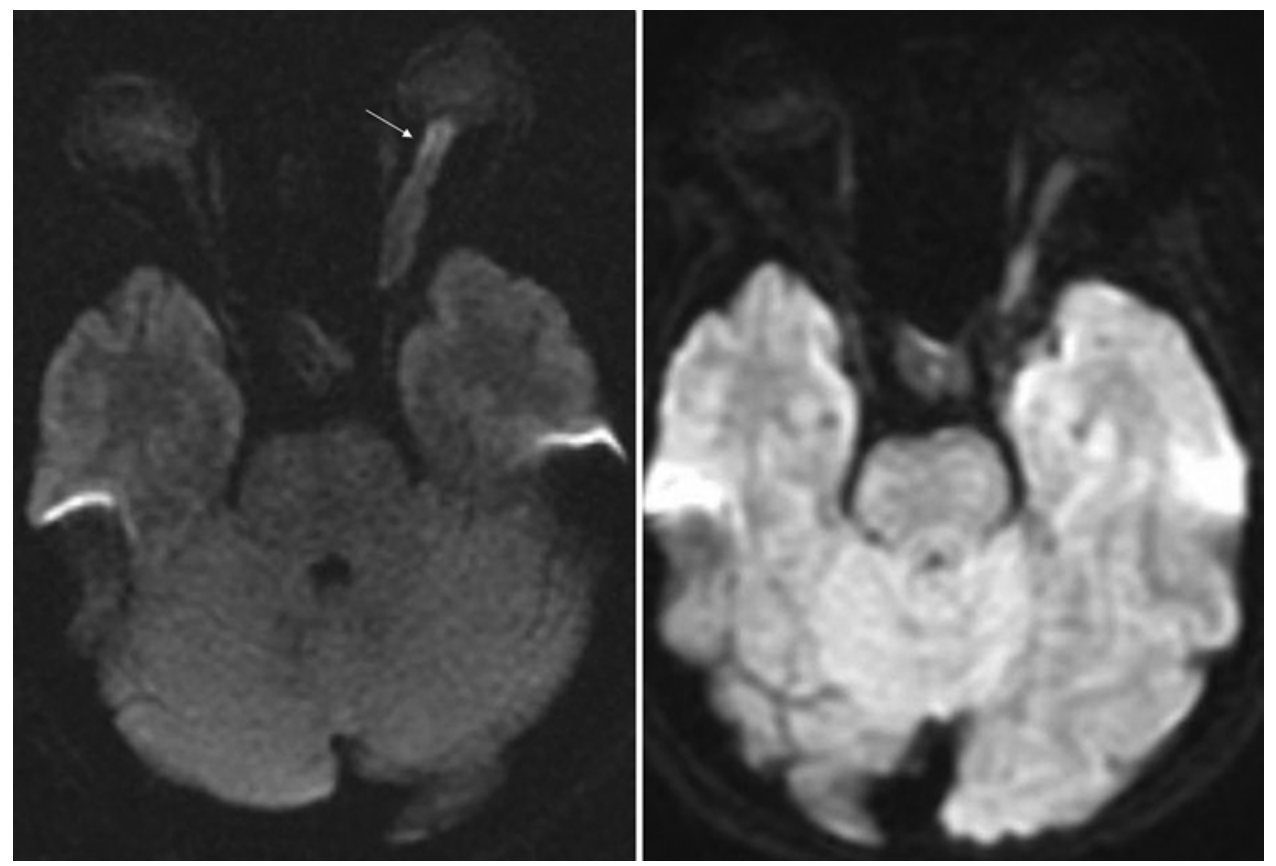

FIG. 3. Axial diffusion-weighted imaging studies. Left: Preoperative image showing a hyperintense signal in the anterior portion of the optic nerve (white arrow), suggesting ischemia. Right: Postoperative image disclosing the same sign along the whole length of the nerve.

disc. ${ }^{19}$ Therefore, in cases of intracanalicular ONSMs, we recommend early surgical intervention before the tumor extends to the middle and anterior portions of the nerve, endangering the central retinal and ciliary arteries (Fig. 4).

\section{Arachnoidal Plane}

Although the whole length of the optic sheath is susceptible to the occurrence of meningiomas, ${ }^{27} \mathrm{Cushing}$ and Eisenhardt considered that the proximity of the foramen would make that area the most probable site of origin, and, as with all meningiomas, ONSMs would then spread along the lines of least resistance. ${ }^{13}$ The occurrence of intracanalicular ONSM appears to be random, as microscopic studies have been unable to reveal any different features of the arachnoid cytoarchitecture between the intracanalicular and intraconal segments of the optic nerve and its sheath. ${ }^{10}$ Arachnoid cap cells that generate primary ONSM tend to completely surround the nerve in its intracanalicular and

\section{TABLE 3. Preoperative and postoperative visual performance}

\begin{tabular}{cclcc}
\hline Case No. & Preop SE & Preop VP & Postop SE & Postop VP \\
\hline 1 & 0.5 & Good & NA & Good \\
\hline 2 & 0.4 & Fair & 0.05 & Poor \\
\hline 3 & 0.6 & Good & 0.6 & Good \\
\hline 4 & 0.6 & Good & 1.3 & Good \\
\hline 5 & 0.5 & Good & 0.5 & Good \\
\hline 6 & $1.0 / 1.0$ & Good & $1.0 / 1.0$ & Good \\
\hline 7 & 0.4 & Fair & EC & Poor \\
\hline 8 & 1.0 & Good & 1.0 & Good \\
\hline
\end{tabular}

$\mathrm{SE}=$ LogMAR Snellen equivalent; $\mathrm{VP}=$ visual performance . intraorbital portion; hence, the tumor is frequently found in the whole circumference of the nerve. ${ }^{31}$

The sheath of the optic nerve and the leptomeninges are analogous structures, and the space between the sheath and the nerve is in continuity with the cerebral subarachnoid space. ${ }^{41}$ The subarachnoid space of the optic nerve contains a complex system of trabeculae and septa filled with cerebrospinal fluid that heterogeneously surrounds the whole nerve, ${ }^{24}$ is relatively narrower in its intracanalicular portion, ${ }^{23}$ and dilates in the presence of tumor in

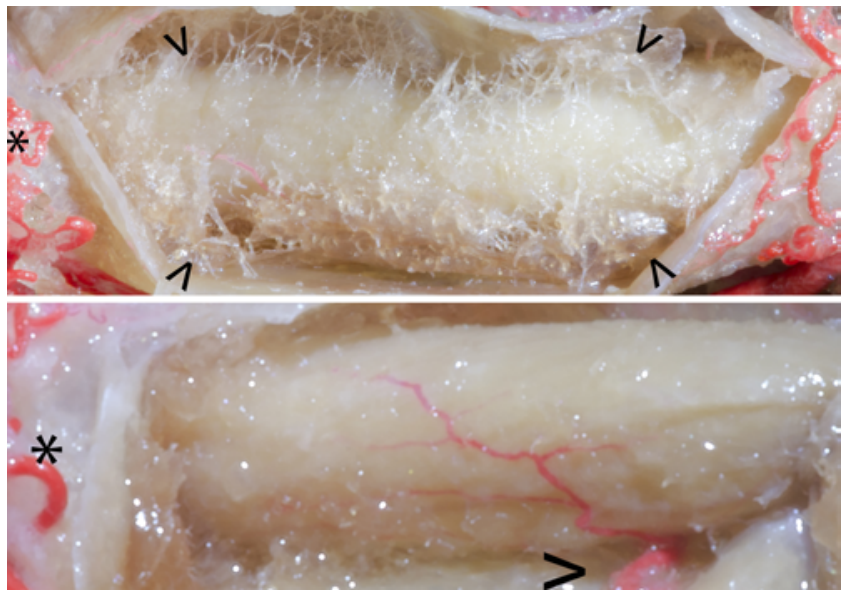

FIG. 4. Anatomical dissections of a left optic nerve and sheath. Upper: Opening the optic sheath reveals a dense arachnoidal trabeculae (arrowheads) serving as a barrier between the dura and the vasculature of the optic nerve. Asterisks in both images indicate the eye globe. Lower: After removing the trabeculae, one can identify, in the inferolateral aspect of the nerve, the central retinal artery (arrowhead) and its branches. Copyright Ossama Al-Mefty. Published with permission. 


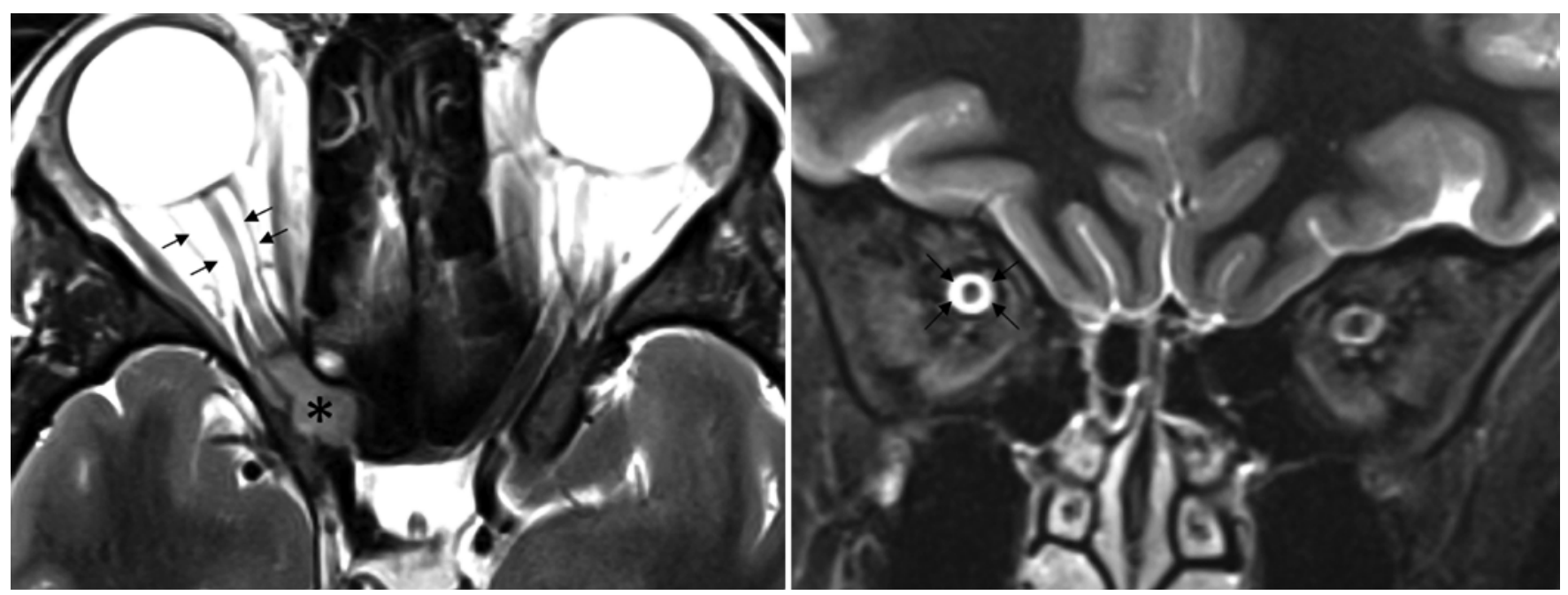

FIG. 5. T2-weighted MRI studies. Left: Axial view revealing an intracanalicular tumor (asterisk) with dilation of the distal subarachnoid space (arrows). Right: The same phenomena can be observed in a coronal plane (arrows).

the retrobulbar portion of the optic sheath (Fig. 5).

It has been demonstrated that primary ONSM has four forms of presentation in relation to the optic nerve (Fig. $6)$. In the first form, tumor may or may not surround the

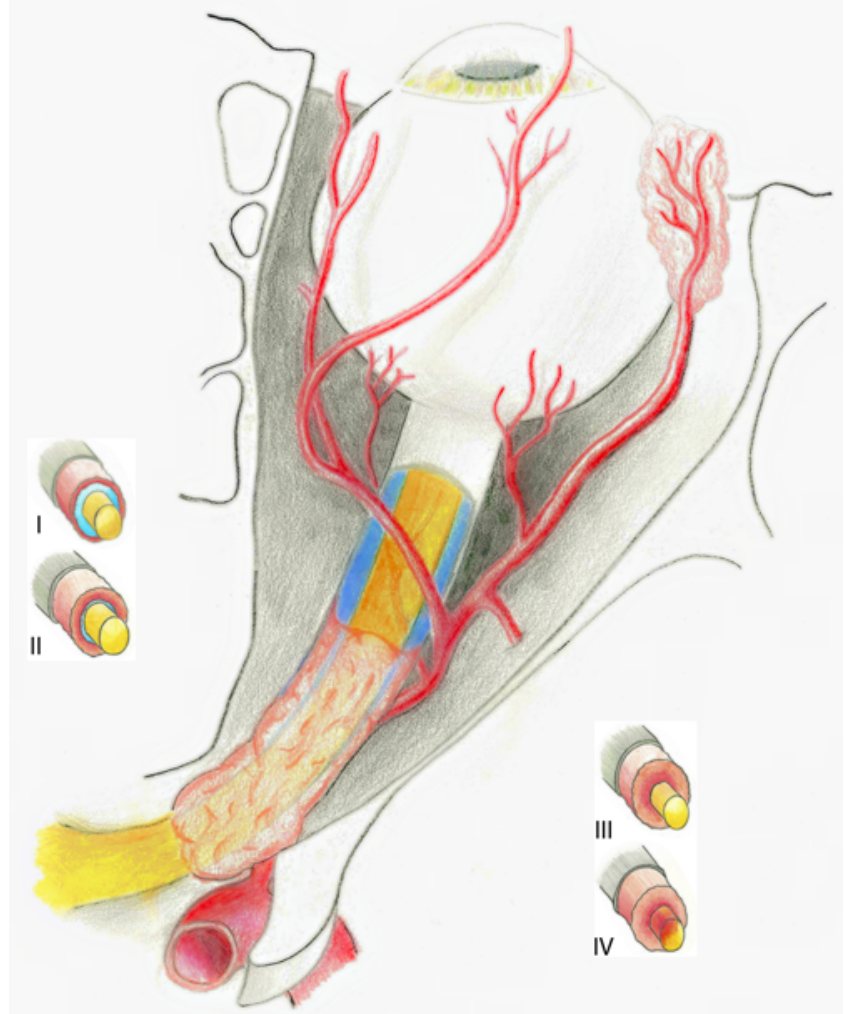

FIG. 6. Artistic representation of the right orbit, superior view, where a tumor (light red) is occupying the optic canal and extending to the posterior third of the intraconal optic nerve, just before the central retinal artery (seen crossing below the nerve). The four forms of ONSMs: I, type 1; II, type 2; III, type 3; IV, type 4. Yellow indicates the optic nerve; blue, CSF at the subarachnoid space; red, tumor; gray, dura (optic nerve sheath). Copyright Anil Can. Published with permission. nerve, but normal subarachnoid space and CSF circulation are found between the tumor and the optic nerve. ${ }^{36,44}$ In a second form, the tumor encircles the nerve, and the subarachnoid space is significantly reduced, although a minimal flow of CSF still separates tumor from the nerve. ${ }^{44}$ In the third form, the CSF interface is no longer present, and the tumor begins to apply pressure to the optic nerve and its peripheral vasculature; ;,45 therefore, incomplete recovery or decline of visual function after excision could be the result of prolonged ischemia. ${ }^{27}$ In the fourth form, the tumor begins to invade the optic nerve's pia. ${ }^{41}$ Thus, complete encirclement of the nerve may be related to an advanced stage of the disease ${ }^{16}$ and early surgical intervention would increase the chances of visual function and successful resection. ${ }^{16,26}$

Intraoperatively, we have noticed that in the first two forms, the presence of a subdural space and an intact arachnoid membrane facilitates tumor dissection without direct contact with the nerve, which has been described by others as well (Fig. 7). ${ }^{28}$ In the third form, resection becomes a more challenging task, as a virtual space separates the nerve from the tumor. In the fourth form, even though patients have probably already presented with irreversible nerve damage, conservative resection with further close observation is preferable.

\section{Conclusions}

Surgery can play a fundamental role in the primary treatment of ONSM, especially in cases in which tumor is limited to the middle or posterior third of the nerve or in which there is still a compressed but preserved arachnoidal space between the nerve and the shocking tumor. Patients with good preoperative vision have a greater chance of a favorable outcome than those with poor vision. Furthermore, our results have shown that, in specific cases, microsurgical total removal of intracanalicular ONSM not only is feasible, but also can improve and stabilize visual function and offer patients a definitive cure for their disease. 

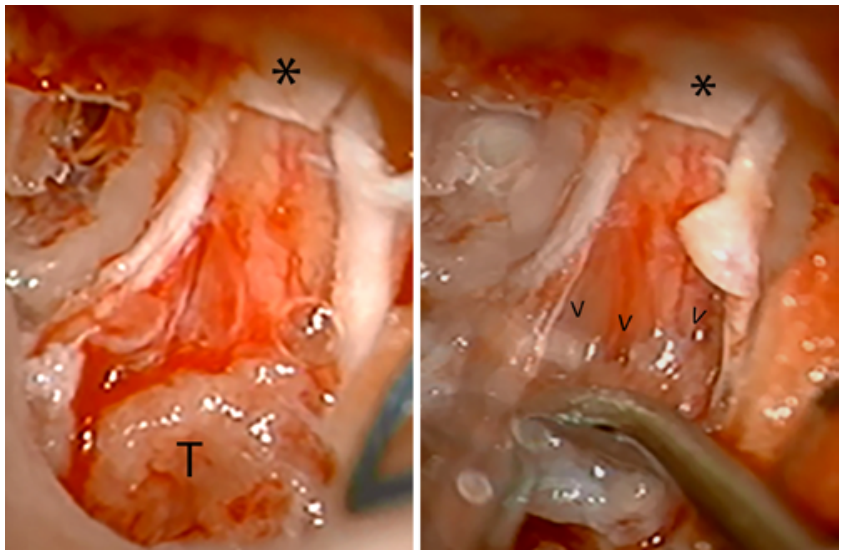

FIG. 7. Intraoperative photographs of an intracanalicular ONSM extending to the posterior third of the optic nerve; the anterior clinoid was removed and the optic sheath was opened. Left: Tumor ( $T$ ) location in relation to the eye globe (asterisks). Right: An intact arachnoidal plane is identified (arrowheads).

\section{References}

1. Abouaf L, Girard N, Lefort T, D'hombres A, Tilikete C, Vighetto A, et al: Standard-fractionated radiotherapy for optic nerve sheath meningioma: visual outcome is predicted by mean eye dose. Int J Radiat Oncol Biol Phys 82:1268-1277, 2012

2. Adams G, Roos DE, Crompton JL: Radiotherapy for optic nerve sheath meningioma: a case for earlier intervention? Clin Oncol (R Coll Radiol) 25:356-361, 2013

3. Al-Mefty O: The supraorbital approach to tuberculum sellae meningiomas, in Al-Mefty $\mathrm{O}$ (ed): Operative Atlas of Meningiomas. Philadelphia: Lippincott-Raven, 1998, pp 30-57

4. Bloch O, Sun M, Kaur G, Barani IJ, Parsa AT: Fractionated radiotherapy for optic nerve sheath meningiomas. J Clin Neurosci 19:1210-1215, 2012

5. Brower JV, Amdur RJ, Kirwan J, Mendenhall WM, Friedman W: Radiation therapy for optic nerve sheath meningioma. Pract Radiat Oncol 3:223-228, 2013

6. Cantore WA: Neural orbital tumors. Curr Opin Ophthalmol 11:367-371, 2000

7. Castel A, Boschi A, Renard L, De Potter P: Optic nerve sheath meningiomas: clinical features, functional prognosis and controversial treatment. Bull Soc Belge Ophtalmol 275:73-78, 2000

8. Charpentier P, Mouriaux F: Total recovery of optic nerve sheath meningioma. BMJ Case Rep 2016:215532, 2016

9. Clark WC, Theofilos CS, Fleming JC: Primary optic nerve sheath meningiomas. Report of nine cases. J Neurosurg 70:37-40, 1989

10. Craig WM, Gogela LJ: Intraorbital meningiomas; a clinicopathologic study. Am J Ophthalmol 32:1663-1680, 1949

11. Craig WM, Gogela LJ: Meningioma of the optic foramen as a cause of slowly progressive blindness; report of three cases. $\mathbf{J}$ Neurosurg 7:44-48, 1950

12. Cristante L: Surgical treatment of meningiomas of the orbit and optic canal: a retrospective study with particular attention to the visual outcome. Acta Neurochir (Wien) 126:2732, 1994

13. Cushing H, Eisenhardt L: Meningiomas. Their Classification, Regional Behaviour, Life History, and Surgical End Results. Springfield, IL: Charles C. Thomas, 1938

14. Dandy WE: Prechiasmal intracranial tumors of the optic nerves. Am J Ophthalmol 5:169-188, 1922

15. Dutton JJ: Optic nerve sheath meningiomas. Surv Ophthalmol 37:167-183, 1992
16. Ebers GC, Girvin JP, Canny CB: A 'possible' optic nerve meningioma. Arch Neurol 37:781-783, 1980

17. Egan RA, Lessell S: A contribution to the natural history of optic nerve sheath meningiomas. Arch Ophthalmol 120:1505-1508, 2002

18. Fineman MS, Augsburger JJ: A new approach to an old problem. Surv Ophthalmol 43:519-524, 1999

19. Francois J, Neetens A, Collette JM: Vascularization of the primary optic pathways. Br J Ophthalmol 42:65-80, 1958

20. Hashiba T, Hashimoto N, Izumoto S, Suzuki T, Kagawa N, Maruno M, et al: Serial volumetric assessment of the natural history and growth pattern of incidentally discovered meningiomas. J Neurosurg 110:675-684, 2009

21. Ito M, Ishizawa A, Miyaoka M, Sato K, Ishii S: Intraorbital meningiomas. Surgical management and role of radiation therapy. Surg Neurol 29:448-453, 1988

22. Kennerdell JS, Maroon JC, Malton M, Warren FA: The management of optic nerve sheath meningiomas. Am J Ophthalmol 106:450-457, 1988

23. Killer HE, Jaggi GP, Flammer J, Miller NR, Huber AR, Mironov A: Cerebrospinal fluid dynamics between the intracranial and the subarachnoid space of the optic nerve. Is it always bidirectional? Brain 130:514-520, 2007

24. Killer HE, Laeng HR, Flammer J, Groscurth P: Architecture of arachnoid trabeculae, pillars, and septa in the subarachnoid space of the human optic nerve: anatomy and clinical considerations. Br J Ophthalmol 87:777-781, 2003

25. Kim JW, Rizzo JF, Lessell S: Controversies in the management of optic nerve sheath meningiomas. Int Ophthalmol Clin 45:15-23, 2005

26. Kuroda R, Nakatani J, Yorimae A, Nakao Y, Ohtori T: Clinical experience of intraorbital optic nerve sheath meningioma-report of eight cases. Neurol Med Chir (Tokyo) 30:468-475, 1990

27. Lee JH, Jeun SS, Evans J, Kosmorsky G: Surgical management of clinoidal meningiomas. Neurosurgery 48:10121021,2001

28. Mark LE, Kennerdell JS, Maroon JC, Rosenbaum AE, Heinz R, Johnson BL: Microsurgical removal of a primary intraorbital meningioma. Am J Ophthalmol 86:704-709, 1978

29. Massof RW: The measurement of vision disability. Optom Vis Sci 79:516-552, 2002

30. Miller NR: Primary tumours of the optic nerve and its sheath. Eye (Lond) 18:1026-1037, 2004

31. Miller NR: Radiation for optic nerve meningiomas: is this the answer? Ophthalmology 109:833-834, 2002

32. Moster ML: Detection and treatment of optic nerve sheath meningioma. Curr Neurol Neurosci Rep 5:367-375, 2005

33. Ortiz O, Schochet SS, Kotzan JM, Kostick D: Radiologicpathologic correlation: meningioma of the optic nerve sheath. AJNR Am J Neuroradiol 17:901-906, 1996

34. Roser F, Nakamura M, Martini-Thomas R, Samii M, Tatagiba M: The role of surgery in meningiomas involving the optic nerve sheath. Clin Neurol Neurosurg 108:470-476, 2006

35. Saeed P, Rootman J, Nugent RA, White VA, Mackenzie IR, Koornneef L: Optic nerve sheath meningiomas. Ophthalmology 110:2019-2030, 2003

36. Samarawickrama C, Frydenberg E, Wells M, Steel T, Ghabrial R: An unusual radiological presentation of optic nerve sheath meningioma. Saudi J Ophthalmol 30:137-139, 2016

37. Schick U, Dott U, Hassler W: Surgical management of meningiomas involving the optic nerve sheath. J Neurosurg 101:951-959, 2004

38. Schick U, Hassler W: Surgical management of tuberculum sellae meningiomas: involvement of the optic canal and visual outcome. J Neurol Neurosurg Psychiatry 76:977-983, 2005

39. Shapey J, Sabin HI, Danesh-Meyer HV, Kaye AH: Diagnosis and management of optic nerve sheath meningiomas. J Clin Neurosci 20:1045-1056, 2013 
40. Shields JA, Shields CL, Scartozzi R: Survey of 1264 patients with orbital tumors and simulating lesions: The 2002 Montgomery Lecture, part 1. Ophthalmology 111:997-1008, 2004

41. Shuangshoti S: Meningioma of the optic nerve. Br J Ophthalmol 57:265-269, 1973

42. Smee RI, Schneider M, Williams JR: Optic nerve sheath meningiomas-non-surgical treatment. Clin Oncol (R Coll Radiol) 21:8-13, 2009

43. Smith JL, Vuksanovic MM, Yates BM, Bienfang DC: Radiation therapy for primary optic nerve meningiomas. J Clin Neuroophthalmol 1:85-99, 1981

44. Spencer WH: Primary neoplasms of the optic nerve and its sheaths: clinical features and current concepts of pathogenetic mechanisms. Trans Am Ophthalmol Soc 70:490-528, 1972

45. Susac JO, Smith JL, Walsh FB: The impossible meningioma. Arch Neurol 34:36-38, 1977

46. Tsutsumi S, Rhoton AL Jr: Microsurgical anatomy of the central retinal artery. Neurosurgery 59:870-879, 2006

47. Turbin RE, Thompson CR, Kennerdell JS, Cockerham KP, Kupersmith MJ: A long-term visual outcome comparison in patients with optic nerve sheath meningioma managed with observation, surgery, radiotherapy, or surgery and radiotherapy. Ophthalmology 109:890-900, 2002

48. Verheggen R, Markakis E, Mühlendyck H, Finkenstaedt M: Symptomatology, surgical therapy and postoperative results of sphenoorbital, intraorbital-intracanalicular and optic sheath meningiomas. Acta Neurochir Suppl 65:95-98, 1996

49. Walsh FB: Abnormalities of the optic disc. Am J Ophthalmol 32:993, 1949

50. Wright JE: Primary optic nerve meningiomas: clinical presentation and management. Trans Sect Ophthalmol Am Acad Ophthalmol Otolaryngol 83:617-625, 1977
51. Wright JE, Call NB, Liaricos S: Primary optic nerve meningioma. Br J Ophthalmol 64:553-558, 1980

52. Wright JE, McNab AA, McDonald WI: Primary optic nerve sheath meningioma. Br J Ophthalmol 73:960-966, 1989

\section{Disclosures}

The authors report no conflict of interest concerning the materials or methods used in this study or the findings specified in this paper.

\section{Author Contributions}

Conception and design: Al-Mefty, Rassi, Prasad, Can. Acquisition of data: Al-Mefty, Pravdenkova. Analysis and interpretation of data: Al-Mefty, Rassi, Prasad. Drafting the article: Al-Mefty, Rassi. Critically revising the article: Al-Mefty, Rassi. Reviewed submitted version of manuscript: all authors. Administrative/technical/material support: Al-Mefty. Study supervision: Al-Mefty.

\section{Supplemental Information}

Online-Only Content

Supplemental material is available with the online version of the article.

Supplementary Table. https://thejns.org/doi/suppl/10.3171/ 2018.4.JNS173080.

\section{Correspondence}

Ossama Al-Mefty: Brigham and Women's Hospital, Harvard Medical School, Boston, MA. almeftyossama@bwh.harvard.edu. 